\title{
ANTIBIOTIC SUSCEPTIBILITY PATTERNS OF AEROBIC BACTERIAL ISOLATES CAUSING WOUND INFECTIONS AMONG THE PATIENTS ATTENDING TO SANTHIRAM GENERAL HOSPITAL, NANDYAL
}

\author{
Mogalapu Ananda Satya Tej1, Sanikommu Sreedevi², G. L. S. Sumanth Kumar³, Jinka Balakrishna4, Satta Naga Sireesha5, \\ Syeda Mariam Seher 6 \\ ${ }^{1}$ Postgraduate Student, Department of Microbiology, Santhiram Medical College and General Hospital, Nandyal, Andhra Pradesh, \\ India. \\ 2Professor and HOD, Department of Microbiology, Santhiram Medical College and General Hospital, Nandyal, Andhra Pradesh, India. \\ ${ }^{3}$ Assistant Professor, Department of Microbiology, Santhiram Medical College and General Hospital, Nandyal, Andhra Pradesh, India. \\ ${ }^{4}$ Assistant Professor, Department of Microbiology, Santhiram Medical College and General Hospital, Nandyal, Andhra Pradesh, India. \\ 5Tutor, Department of Microbiology, Santhiram Medical College and General Hospital, Nandyal, Andhra Pradesh, India. \\ ${ }^{6}$ Postgraduate Student, Department of Microbiology, Santhiram Medical College and General Hospital, Nandyal, Andhra Pradesh, \\ India.
}

\section{BACKGROUND}

\section{ABSTRACT}

The increasing trends in the rate of the antibiotic resistance have now become a serious and an increasingly common concern with severe implications, especially in the surgical departments. These multidrug resistance patterns which include ESBLs, AmpC $\beta$ lactamases and metallo-ß-lactamases have emerged as the most worrisome mechanisms of resistance among the gram-negative bacteria, which pose a therapeutic challenge to the healthcare settings.

\section{MATERIALS AND METHODS}

This descriptive study was undertaken to evaluate the profile of aerobic pyogenic bacteria in various pus isolates along with the changing trends in antimicrobial resistance in a tertiary hospital in Nandyal from January 2017 to December 2017 . A total of 283 bacterial isolates from 577 clinical samples, which were received over a period of one year were processed. After their identification and their antimicrobial susceptibility testing, they were then screened for the multidrug resistance.

\section{RESULTS}

Among the 283 isolates, most predominant organism was Escherichia coli 63 (22.18\%) followed by Pseudomonas aeruginosa 60 $(21.13 \%)$ and Staphylococcus aureus 58 (20.42\%). The antibiogram of gram-positive cocci revealed that they were most susceptible to Vancomycin (100\%) and Linezolid (100\%). Gram-negative Bacilli are susceptible to Imipenem (96.23\%), Cefoperazone + Sulbactam (77.22\%) and Netilmicin (75.47\%). Of the 212 gram-negative isolates, 143 (67.45\%) were ESBL producers followed by 36 (16.98\%) AmpC producers and 7 (3.30\%) metallo- $\beta$-lactamase (MBL) producers. The major ESBL and AmpC producer was Klebsiella pneumoniae, while the MBL production was mainly observed in Pseudomonas aeruginosa.

\section{CONCLUSION}

The high prevalence of the multidrug resistant isolates emphasises the need for a continuous surveillance in the healthcare settings to detect the resistant strains, strict guidelines for the antibiotic therapy and the implementation of infection control mea sures to reduce the increasing burden of antibiotic resistance.

\section{KEY WORDS}

Pus, Pyogenic, Antibiotic Susceptibility Pattern, Multidrug Resistance, MBL, ESBL, AmpC.

HOW TO CITE THIS ARTICLE: Tej MAS, Sreedevi S, Kumar GLSS, et al. Antibiotic susceptibility patterns of aerobic bacterial isolates causing wound infections among the patients attending to Santhiram Medical College, Nandyal. J. Evolution Med. Dent. Sci. 2018;7(30):3360-3364, DOI: 10.14260/jemds/2018/758

\section{BACKGROUND}

Pyogenic infection is generally caused by one of the pyogenic bacteria and characterised by severe local inflammation, usually with pus formation. Pyogenic infections can be either endogenous or exogenous. A discontinuity in the skin can provide an entryway for these surface bacteria into the body and the bacteria multiply and extend into the cut.

'Financial or Other Competing Interest': None.

Submission 13-06-2018, Peer Review 07-07-2018,

Acceptance 13-07-2018, Published 23-07-2018.

Corresponding Author:

Mogalapu Ananda Satya Tej,

Department of Microbiology,

Santhiram Medical College and General Hospital,

NH-18, Nandyal-518501, Kurnool District, Andhra Pradesh, India.

E-mail:anandstej@gmail.com

DOI: $10.14260 /$ jemds $/ 2018 / 758$

\section{(c) (i) $\$$}

The body's defence mechanism brings immune cells into the area to fight against the bacteria. As a result, accumulation of these cells produces the thick whitish pus. With the increase of antibiotic use in the recent years, the emergence of resistance of the bacteria is also at rise. Various studies have been consistent enough to show a predictable bacterial profile and their resistance patterns in the pyogenic wound infections. This helps a clinician who intends to start empirical treatment to his patients, while laboratory culture reports are awaited.

This study was undertaken to evaluate the profile of aerobic pyogenic bacteria in various pus isolates along with the changing trends in antimicrobial resistance in a tertiary hospital in Nandyal from January 2017 to December 2017.

\section{MATERIALS AND METHODS}

This was a descriptive study. A total number of 577 pus samples received for aerobic culture and sensitivity from 
IPDs and OPDs of various departments to Microbiology Central Laboratory of Santhiram General Hospital, Nandyal during a period from January 2017 to December 2017 were included in the study.

The samples were inoculated on Blood Agar, Chocolate Agar, MacConkey's Agar and Nutrient Agar media as soon as they were received and incubated at $37^{\circ} \mathrm{C}$ for 24 hours under aerobic condition in incubator, and under sterile conditions. If there was no growth within 24 hours, the plates were further incubated for 24 hours. If growth was seen, the bacterial species were identified on basis of colony morphology, morphology of bacteria, staining characters, culture characteristics and biochemical reactions according to standard techniques. For testing the antibiotic sensitivity, Kirby Bauer's Disk Diffusion method was used and the isolates were inoculated uniformly on Muller-Hinton agar plates and the antibiotic discs were placed firmly on the surface of the medium with sterile forceps. After incubation at $37^{\circ} \mathrm{C}$ for $18-24$ hours, the zone of inhibition was noted.[1,2] Results were interpreted comparing with the standard zone size as per Clinical Laboratory Standard Institution (CLSI) guidelines. ${ }^{[3]}$

Standard antibiotics like Amikacin (30 mcg), Amoxyclav (20/10 mcg), Ampicillin (10 mcg), Aztreonam (30 mcg), Ceftazidime Clavulanic Acid (30/10 mcg), Ceftazidime (30 mcg), Clindamycin (2 mcg), Cefoperazone + Sulbactam (75/10 mcg), Ciprofloxacin (5 mcg), Ceftriaxone (30 mcg), Cefotaxime (5 mcg), Cefoxitin (30 mcg), Cefazolin (30 mcg), Doxycycline (30 mcg), Erythromycin (15 mcg), Gentamycin (10 mcg), Imipenem (10 mcg), Linezolid (30 mcg), Netilmicin (30 mcg), Penicillin-G (10 units), Piperacillin (100 mcg), Piperacillin + Tazobactam (30/6 mcg), Sparfloxacin (5 mcg), Teicoplanin $(30 \mathrm{mcg})$ and Vancomycin $(30 \mathrm{mcg})^{[4]}$ were tested. All antibiotic discs were procured from HiMedia, Mumbai, India.

Isolates resistant to third generation cephalosporins were tested for ESBL production and isolates showing resistance to imipenem were tested for MBL production. Phenotypic detection of ESBL was done by the double disk diffusion method using ceftazidime $(30 \mu \mathrm{g})$ and ceftazidime-clavulanic acid $(30 \mu \mathrm{g} / 10 \mu \mathrm{g})$. The strains were screened for the AmpC $\beta$-lactamase production by the disc antagonism test. Imipenem resistant isolates were screened for production of MBL by double disc diffusion test using commercially available imipenem $(10 \mu \mathrm{g})$ and imipenem/EDTA $(10+750$ $\mu \mathrm{g})$.

\section{RESULTS}

Out of total 577 pus samples received, 491 (85.1\%) were from inpatients and $86(14.90 \%)$ were from outpatient departments [Figure 1].

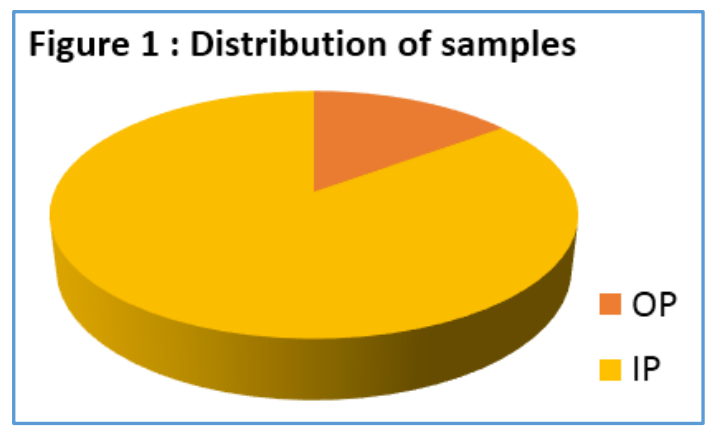

265 (45.93\%) samples were culture positive and 312 (54.07\%) were culture negative [Figure 2].

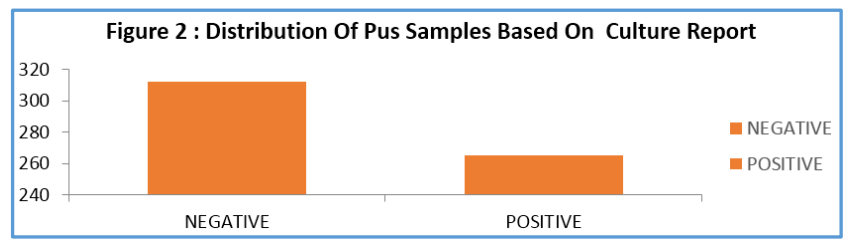

265 culture positive samples yielded 283 isolates. 93\% (246) showed monomicrobial growth and 7\% (19) showed mixed growth [Figure 3].

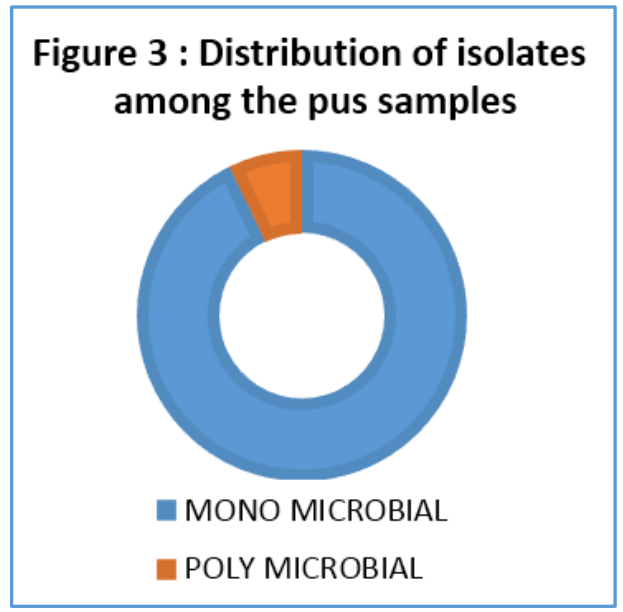

Out of 283 samples, seventy one (25.09\%) of the isolates were gram positive and 212 (74.91\%) were gram negative [Figure 4].

\section{Figure 4 : Distribution of isolates}

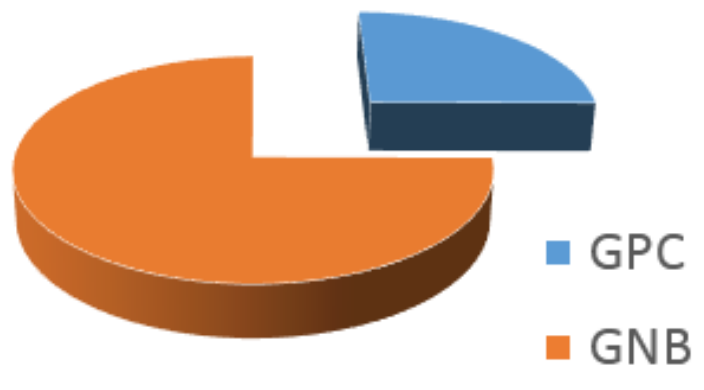

Among 265 culture positive samples, 182 (68.68\%) were from male patients and $83(31.32 \%)$ were from female patients [Figure 5].

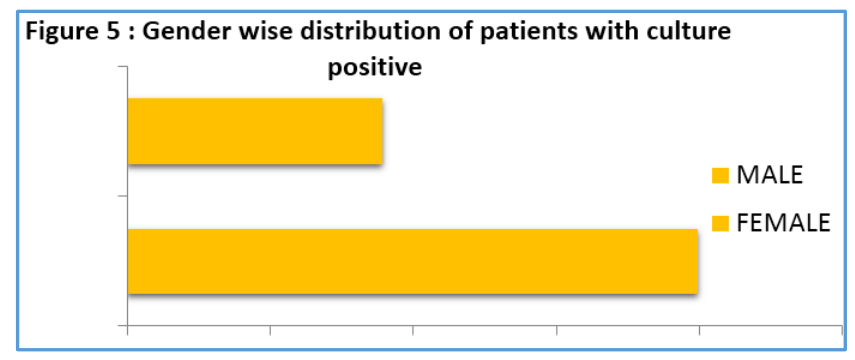

Majority of the cultures were positive from 51 - 60 years' age group comprising of $22 \%$ (59) [Figure 6]. 


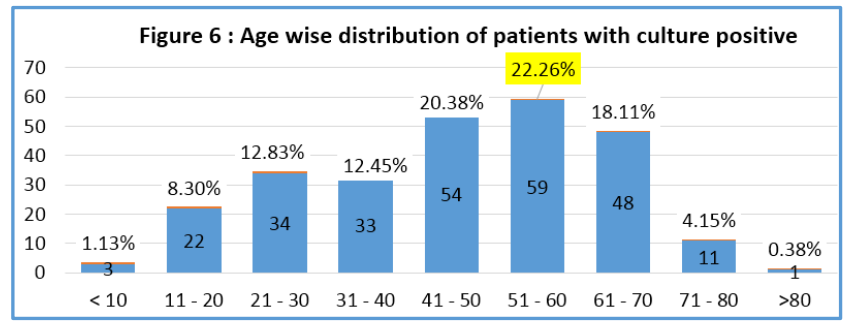

The department-wise distribution of pus samples revealed that surgery dept. was the highest contributors (72.79\%) followed by Orthopaedics (12.82\%), Gynaecology and Obstetrics (5.55\%), Medicine (5.37\%), Paediatrics (1.21\%), TB and CD (1.21\%), DVL (0.69\%) and ENT $(0.35 \%)$ departments [Table 1].

\begin{tabular}{|c|c|c|}
\hline Department & Total Samples & Culture Positive \\
\hline Surgery & $402(69.67 \%)$ & $180(44.78 \%)$ \\
\hline Orthopaedics & $74(12.82 \%)$ & $41(55.41 \%)$ \\
\hline ICU & $34(5.89 \%)$ & $12(35.29 \%)$ \\
\hline OBG & $32(5.55 \%)$ & $20(62.50 \%)$ \\
\hline Medicine & $15(2.60 \%)$ & $4(26.67 \%)$ \\
\hline Paediatrics & 7 (1.21\%) & $2(28.57 \%)$ \\
\hline TB and CD & $7(1.21 \%)$ & $4(57.14 \%)$ \\
\hline DVL & $4(0.69 \%)$ & $1(25.00 \%)$ \\
\hline ENT & $2(0.35 \%)$ & $1(50.00 \%)$ \\
\hline Total & $577(100.00 \%)$ & $265(45.58 \%)$ \\
\hline
\end{tabular}

Organism-wise distribution of positive cultures showed highest isolation of Escherichia coli followed by Pseudomonas, Staphylococcus and Klebsiella. Among the gram-positive bacteria isolated, most predominant organism was Staphylococcus aureus 58 (20.42\%) followed by Streptococcus pyogenes 8 (2.82\%), Enterococcus species 3 $(1.06 \%)$ and CONS (Staphylococcus epidermidis) 2 (0.70\%). Among the gram-positive bacteria isolated, most predominant organism was Escherichia coli 63 (22.18\%) followed by Pseudomonas aeruginosa 60 (21.13\%), Klebsiella pneumoniae 57 (20.07\%) and Proteus sp. 16 (5.63\%), Citrobacter 15 (5.28\%) and Enterobacter 1 (0.35\%). One fungal isolate was identified as Candida spp. (0.35\%) [Table2].

\begin{tabular}{|c|c|}
\hline Organisms Distribution & Number \\
\hline Escherichia coli & $63(22.18 \%)$ \\
\hline Pseudomonas aeruginosa & $60(21.13 \%)$ \\
\hline Staphylococcus aureus & $58(20.42 \%)$ \\
\hline Klebsiella pneumoniae & $57(20.07 \%)$ \\
\hline Proteus species & $16(5.63 \%)$ \\
\hline
\end{tabular}

\begin{tabular}{|c|c|}
\hline Citrobacter species & $15(5.28 \%)$ \\
\hline Streptococcus pyogenes & $8(2.82 \%)$ \\
\hline Enterococcus species & $3(1.06 \%)$ \\
\hline Cons & $2(0.70 \%)$ \\
\hline Enterobacter & $1(0.35 \%)$ \\
\hline Candida & $1(0.35 \%)$ \\
\hline Total & $\mathbf{2 8 4}(\mathbf{1 0 0 . 0 0 \% )}$ \\
\hline Table 2. Organism-Wise distribution of Culture Positivity
\end{tabular}

The Antibiogram of gram-positive cocci revealed that most isolates were susceptible to Vancomycin (100\%) and linezolid (100\%) [Table-3] [Table-4].

\begin{tabular}{|c|c|c|c|c|}
\hline \multirow{2}{*}{$\begin{array}{c}\text { Name of } \\
\text { Antibiotics }\end{array}$} & $\begin{array}{c}\text { Staphylococcus } \\
\text { aureus (n= 58) }\end{array}$ & \multicolumn{2}{c|}{$\begin{array}{c}\text { CONS } \\
\text { (n= 2) }\end{array}$} \\
\cline { 2 - 5 } & Sensitive & Resistant & Sensitive & Resistant \\
\hline Amoxyclav & $46.55 \%$ & $53.45 \%$ & $0.00 \%$ & $100.00 \%$ \\
\hline Clindamycin & $82.76 \%$ & $17.24 \%$ & $50.00 \%$ & $50.00 \%$ \\
\hline Ciprofloxacin & $82.76 \%$ & $17.24 \%$ & $50.00 \%$ & $50.00 \%$ \\
\hline Cefoxitin & $98.28 \%$ & $1.72 \%$ & $100.00 \%$ & $0.00 \%$ \\
\hline Cefazolin & $89.66 \%$ & $10.34 \%$ & $50.00 \%$ & $50.00 \%$ \\
\hline Erythromycin & $56.90 \%$ & $43.10 \%$ & $50.00 \%$ & $50.00 \%$ \\
\hline Gentamycin & $87.93 \%$ & $12.07 \%$ & $50.00 \%$ & $50.00 \%$ \\
\hline Linezolid & $100.00 \%$ & $0.00 \%$ & $100.00 \%$ & $0.00 \%$ \\
\hline Netilmicin & $91.38 \%$ & $8.62 \%$ & $100.00 \%$ & $0.00 \%$ \\
\hline Penicillin-G & $10.34 \%$ & $89.66 \%$ & $0.00 \%$ & $100.00 \%$ \\
\hline Sparfloxacin & $94.83 \%$ & $5.17 \%$ & $100.00 \%$ & $0.00 \%$ \\
\hline Teicoplanin & $100.00 \%$ & $0.00 \%$ & $100.00 \%$ & $0.00 \%$ \\
\hline Vancomycin & $100.00 \%$ & $0.00 \%$ & $100.00 \%$ & $0.00 \%$ \\
\hline \multicolumn{6}{|c|}{ Table 3. Antibiogram of Gram-Positive Cocci } \\
(Staphylococcus species) \\
\hline
\end{tabular}

\begin{tabular}{|c|c|c|c|c|}
\hline \multirow{2}{*}{$\begin{array}{c}\text { Name of } \\
\text { Antibiotics }\end{array}$} & $\begin{array}{c}\text { Streptococcus } \\
\text { Pyogenes (n= 8) }\end{array}$ & \multicolumn{2}{c|}{$\begin{array}{c}\text { Enterococcus } \\
\text { (n= 3) }\end{array}$} \\
\cline { 2 - 5 } & Sensitive & Resistant & Sensitive & Resistant \\
\hline Amoxyclav & $75.00 \%$ & $25.00 \%$ & $33.33 \%$ & $66.67 \%$ \\
\hline Ampicillin & $75.00 \%$ & $25.00 \%$ & $33.33 \%$ & $66.67 \%$ \\
\hline Aztreonam & $100.00 \%$ & $0.00 \%$ & $33.33 \%$ & $66.67 \%$ \\
\hline Clindamycin & $50.00 \%$ & $50.00 \%$ & $33.33 \%$ & $66.67 \%$ \\
\hline Ciprofloxacin & $50.00 \%$ & $50.00 \%$ & $100.00 \%$ & $0.00 \%$ \\
\hline Cefazolin & $50.00 \%$ & $50.00 \%$ & $100.00 \%$ & $0.00 \%$ \\
\hline Doxycycline & $100.00 \%$ & $0.00 \%$ & $100.00 \%$ & $0.00 \%$ \\
\hline Erythromycin & $37.50 \%$ & $62.50 \%$ & $100.00 \%$ & $0.00 \%$ \\
\hline Gentamycin & $50.00 \%$ & $50.00 \%$ & $100.00 \%$ & $0.00 \%$ \\
\hline Linezolid & $100.00 \%$ & $0.00 \%$ & $66.67 \%$ & $33.33 \%$ \\
\hline Penicillin-G & $25.00 \%$ & $75.00 \%$ & $0.00 \%$ & $100.00 \%$ \\
\hline Teicoplanin & $100.00 \%$ & $0.00 \%$ & $66.67 \%$ & $33.33 \%$ \\
\hline Vancomycin & $100.00 \%$ & $0.00 \%$ & $100.00 \%$ & $0.00 \%$ \\
\hline \multicolumn{6}{|c|}{$\begin{array}{c}\text { Table 4. Antibiogram of Gram-Positive Cocci } \\
\text { (Streptococcus and Enterococcus species) }\end{array}$} \\
\hline \multicolumn{5}{|c|}{}
\end{tabular}

\begin{tabular}{|c|c|c|c|c|c|c|c|c|c|c|}
\hline \multirow[t]{2}{*}{$\begin{array}{c}\text { Name of } \\
\text { Antibiotics }\end{array}$} & \multicolumn{2}{|c|}{$\begin{array}{c}\text { Escherichia coli } \\
(n=63)\end{array}$} & \multicolumn{2}{|c|}{$\begin{array}{c}\text { Klebsiella } \\
\text { pneumoniae } \\
(\mathrm{n}=57)\end{array}$} & \multicolumn{2}{|c|}{$\begin{array}{c}\text { Proteus } \\
\text { SPP }(n=16)\end{array}$} & \multicolumn{2}{|c|}{$\begin{array}{l}\text { Citrobacter Spp. } \\
\quad(n=15)\end{array}$} & \multicolumn{2}{|c|}{$\begin{array}{l}\text { Enterobacter } \\
\qquad(n=1)\end{array}$} \\
\hline & Sensitive & Resistan & Sensitive & Resistant & Sensitive & Resistant & Sensitive & Resistant & Sensitive & Resistant \\
\hline Amikacin & $90.48 \%$ & $9.52 \%$ & $61.40 \%$ & $38.60 \%$ & $56.25 \%$ & $43.75 \%$ & $60.00 \%$ & $40.00 \%$ & $100.00 \%$ & $0.00 \%$ \\
\hline Amoxyclav & $11.11 \%$ & $88.89 \%$ & $5.26 \%$ & $94.74 \%$ & $12.50 \%$ & $87.50 \%$ & $6.67 \%$ & $93.33 \%$ & $0.00 \%$ & $100.00 \%$ \\
\hline Ampicillin & $7.94 \%$ & $92.06 \%$ & $3.51 \%$ & $96.49 \%$ & $12.50 \%$ & $87.50 \%$ & $6.67 \%$ & $93.33 \%$ & $0.00 \%$ & $100.00 \%$ \\
\hline Ceftazidime & $36.51 \%$ & $63.49 \%$ & $15.79 \%$ & $84.21 \%$ & $31.25 \%$ & $68.75 \%$ & $20.00 \%$ & $80.00 \%$ & $0.00 \%$ & $100.00 \%$ \\
\hline $\begin{array}{c}\text { Cefoperazone }+ \\
\text { Sulbactam }\end{array}$ & $79.37 \%$ & $20.63 \%$ & $64.91 \%$ & $35.09 \%$ & $87.50 \%$ & $12.50 \%$ & $93.33 \%$ & $6.67 \%$ & $100.00 \%$ & $0.00 \%$ \\
\hline Ciprofloxacin & $39.68 \%$ & $58.73 \%$ & $31.58 \%$ & $68.42 \%$ & $75.00 \%$ & $25.00 \%$ & $60.00 \%$ & $40.00 \%$ & $100.00 \%$ & $0.00 \%$ \\
\hline
\end{tabular}




\begin{tabular}{|c|c|c|c|c|c|c|c|c|c|c|}
\hline Ceftriaxone & $34.92 \%$ & $65.08 \%$ & $15.79 \%$ & $84.21 \%$ & $43.75 \%$ & $56.25 \%$ & $20.00 \%$ & $80.00 \%$ & $0.00 \%$ & $100.00 \%$ \\
\hline Gentamycin & $85.71 \%$ & $14.29 \%$ & $56.14 \%$ & $43.86 \%$ & $62.50 \%$ & $37.50 \%$ & $66.67 \%$ & $33.33 \%$ & $100.00 \%$ & $0.00 \%$ \\
\hline Imipenem & $98.41 \%$ & $1.59 \%$ & $96.49 \%$ & $3.51 \%$ & $93.75 \%$ & $6.25 \%$ & $100.00 \%$ & $0.00 \%$ & $100.00 \%$ & $0.00 \%$ \\
\hline Netilmicin & $87.30 \%$ & $12.70 \%$ & $64.91 \%$ & $35.09 \%$ & $56.25 \%$ & $43.75 \%$ & $73.33 \%$ & $26.67 \%$ & $100.00 \%$ & $0.00 \%$ \\
\hline Piperacillin & $26.98 \%$ & $73.02 \%$ & $19.30 \%$ & $80.70 \%$ & $62.50 \%$ & $37.50 \%$ & $40.00 \%$ & $60.00 \%$ & $0.00 \%$ & $100.00 \%$ \\
\hline $\begin{array}{c}\text { Piperacillin+ } \\
\text { Tazobactam }\end{array}$ & $73.02 \%$ & $26.98 \%$ & $57.89 \%$ & $42.11 \%$ & $87.50 \%$ & $12.50 \%$ & $73.33 \%$ & $26.67 \%$ & $100.00 \%$ & $0.00 \%$ \\
\hline Sparfloxacin & $46.03 \%$ & $53.97 \%$ & $52.63 \%$ & $47.37 \%$ & $62.50 \%$ & $37.50 \%$ & $86.67 \%$ & $13.33 \%$ & $100.00 \%$ & $0.00 \%$ \\
\hline \multicolumn{18}{|c|}{ Table 5. Antibiogram of Enterobacteriaceae members } \\
\hline
\end{tabular}

Gram-negative Bacilli are susceptible to Imipenem (96.23\%), Cefoperazone + Sulbactam (77.22\%), Netilmicin (75.47\%), Amikacin (75.00\%) [Table-5] [Table-6].

\begin{tabular}{|c|c|c|}
\hline \multirow{2}{*}{ Name of Antibiotics } & \multicolumn{2}{|c|}{ Pseudomonas Spp. } \\
\cline { 2 - 3 } & Sensitive & Resistant \\
\hline Amikacin & $80.00 \%$ & $20.00 \%$ \\
\hline Ciprofloxacin & $80.00 \%$ & $20.00 \%$ \\
\hline Cefotaxime & $40.00 \%$ & $60.00 \%$ \\
\hline Gentamycin & $75.00 \%$ & $25.00 \%$ \\
\hline Imipenem & $93.33 \%$ & $6.67 \%$ \\
\hline Netilmicin & $78.33 \%$ & $21.67 \%$ \\
\hline Piperacillin & $70.00 \%$ & $30.00 \%$ \\
\hline Piperacillin + Tazobactam & $83.33 \%$ & $16.67 \%$ \\
\hline Table 6. Antibiogram of Non-Fermenters \\
\hline
\end{tabular}

Of the 212 gram-negative isolates, 143 (67.45\%) were ESBL producers followed by $36(16.98 \%)$ AmpC producers and $7(3.30 \%)$ metallo- $\beta$-lactamase (MBL) producers. The Major ESBL producer was Klebsiella pneumoniae (32.87\%) followed by Escherichia coli $(27.27 \%)$ and Pseudomonas aeruginosa $(25.17 \%)$. The $\mathrm{AmpC}$ production was also maximally seen in Klebsiella pneumoniae (55.56\%), while the MBL production was mainly observed in Pseudomonas aeruginosa (57.14\%) [Table-7].

\begin{tabular}{|c|c|c|c|c|c|c|}
\hline \multirow{2}{*}{ Organisms } & \multicolumn{2}{|c|}{ ESBL } & \multicolumn{2}{c|}{ AMPC } & \multicolumn{2}{c|}{ MBL } \\
\cline { 2 - 7 } & No. & & No. & $\%$ & No. & $\%$ \\
\hline Escherichia coli & 39 & $27.27 \%$ & 13 & $36.11 \%$ & 1 & $14.29 \%$ \\
\hline $\begin{array}{c}\text { Pseudomonas } \\
\text { aeruginosa }\end{array}$ & 36 & $25.17 \%$ & 0 & $0.00 \%$ & 4 & $57.14 \%$ \\
\hline $\begin{array}{c}\text { Klebsiella } \\
\text { pneumoniae }\end{array}$ & 47 & $32.87 \%$ & 20 & $55.56 \%$ & 1 & $14.29 \%$ \\
\hline Proteus species & 8 & $5.59 \%$ & 2 & $5.56 \%$ & 1 & $14.29 \%$ \\
\hline Citrobacter species & 12 & $8.39 \%$ & 1 & $2.78 \%$ & 0 & $0.00 \%$ \\
\hline Enterobacter & 1 & $0.70 \%$ & 0 & $0.00 \%$ & 0 & $0.00 \%$ \\
\hline Total & 143 & $100.00 \%$ & 36 & $100.00 \%$ & 7 & $100.00 \%$ \\
\hline Table 7. Organism-Wise distribution of Multidrug \\
Resistant Isolates
\end{tabular}

Highest number of MDR isolates were recovered from samples received from surgery department (65.03\%) followed by Orthopaedics (13.99\%) and Gynaecology and Obstetrics (12.59\%) [Table-8].

\begin{tabular}{|c|c|c|c|}
\hline & $\begin{array}{c}\text { ESBL } \\
(n=143)\end{array}$ & $\begin{array}{c}\text { AMPC } \\
(n=36)\end{array}$ & $\begin{array}{c}\text { MBL } \\
(n=7)\end{array}$ \\
\hline Surgery & $93(65.03 \%)$ & $26(72.22 \%)$ & $4(57.14 \%)$ \\
\hline Orthopaedics & $20(13.99 \%)$ & $4(11.11 \%)$ & $3(42.86 \%)$ \\
\hline $\begin{array}{l}\text { Gynaecology and } \\
\text { Obstetrics }\end{array}$ & 18 (12.59\%) & $2(5.56 \%)$ & $0(0.00 \%)$ \\
\hline ICU & $8(5.59 \%)$ & $3(8.33 \%)$ & $0(0.00 \%)$ \\
\hline Medicine & $2(1.40 \%)$ & $1(2.78 \%)$ & $0(0.00 \%)$ \\
\hline Paediatrics & $0(0.00 \%)$ & $0(0.00 \%)$ & $0(0.00 \%)$ \\
\hline TB and CD & $1(0.70 \%)$ & $0(0.00 \%)$ & $0(0.00 \%)$ \\
\hline DVL & $1(0.70 \%)$ & $0(0.00 \%)$ & $0(0.00 \%)$ \\
\hline ENT & $0(0.00 \%)$ & $0(0.00 \%)$ & $0(0.00 \%)$ \\
\hline Total & $\begin{array}{c}143 \\
(100.00 \%)\end{array}$ & $\begin{array}{c}36 \\
(100.00 \%)\end{array}$ & $\begin{array}{c}7 \\
(100.00 \%)\end{array}$ \\
\hline \multicolumn{4}{|c|}{$\begin{array}{c}\text { Table 8. Department-Wise distribution of Multidrug } \\
\text { Resistant Isolates }\end{array}$} \\
\hline
\end{tabular}

\section{DISCUSSION}

The present study revealed that among the gram-positive bacteria isolated, most predominant organism was Staphylococcus aureus 58 (20.42\%) followed by Streptococcus pyogenes 8 (2.82\%), enterococcus species $3(1.06 \%)$ and CONS (Staphylococcus epidermidis) 2 (0.70\%). Among the gram-positive bacteria isolated, most predominant organism was Escherichia coli 63 (22.18\%) followed by Pseudomonas aeruginosa 60 (21.13\%), Klebsiella pneumoniae 57 (20.07\%) and Proteus sp. 16 (5.63\%) Citrobacter 15 (5.28\%) and enterobacter $1(0.35 \%)$. One fungal isolate was identified as Candida spp $(0.35 \%)$. Dominance of gram-negative bacteria as the causative agent of pyogenic lesions is seen which is supported by Zubair et al,[5] Agnihotri $\mathrm{N}$ et al,[6] Ghosh A et al[7] and Basu S et al.[8]

The department wise distribution of pus samples revealed that surgery dept. was the highest contributors (72.79\%) followed by Orthopaedics (12.82\%), Gynaecology and Obstetrics (5.55\%), Medicine (5.37\%), Paediatrics (1.21\%), TB and CD (1.21\%), DVL (0.69\%) and ENT (0.35\%) departments.

The Antibiogram of Staphylococcus aureus revealed that the Vancomycin (100\%), teicoplanin (100\%) and linezolid $(100 \%)$ were the most susceptible drugs. The Antibiogram of coagulase negative staphylococci revealed that the Vancomycin (100\%), teicoplanin (100\%), linezolid (100\%), sparfloxacin (100\%), netilmicin (100\%) and cefoxitin (100\%) were the most susceptible drugs. The Antibiogram of streptococci revealed that the Vancomycin (100\%), Teicoplanin (100\%), Linezolid (100\%), Doxycycline (100\%) and Aztreonam (100\%) were the most susceptible drugs. The Antibiogram of Enterococci revealed that the Vancomycin (100\%), Ciprofloxacin (100\%), Cefazolin (100\%), Doxycycline (100\%), Erythromycin (100\%), Gentamycin $(100 \%)$ and linezolid $(100 \%)$ were the most susceptible drugs.

The Antibiogram of Escherichia coli revealed that the Imipenem (98.41\%) was the most susceptible drug followed by Amikacin (90.48\%) and Netilmicin (87.30\%). The Antibiogram of Klebsiella pneumoniae revealed that the Imipenem (96.49\%) was the most susceptible drug followed by Piperacillin + Tazobactam (64.91\%) and Netilmicin (64.91\%). The Antibiogram of Proteus species revealed that the Imipenem (93.75\%) was the most susceptible drug followed by Piperacillin + Tazobactam (87.50\%) and Netilmicin (87.50\%). The Antibiogram of Citrobacter species revealed that the Imipenem $(100.00 \%)$ was the most susceptible drug followed by Cefoperazone + sulbactam (93.33\%) and Sparfloxacin (86.67\%). The Antibiogram of Klebsiella pneumoniae revealed that the Amikacin (100.00\%), 
Cefoperazone + Sulbactam (100.00\%), Ciprofloxacin (100.00\%), Gentamycin (100.00\%), Imipenem (100.00\%), Netilmicin (100.00\%), Piperacillin + Tazobactam (100.00\%) and Sparfloxacin (100.00\%) were the most susceptible drugs.

The Antibiogram of gram-positive cocci revealed that the Vancomycin (100\%), teicoplanin (100\%) and linezolid $(100 \%)$ were the most susceptible drugs. Gram-negative Bacilli are susceptible to Imipenem (96.23\%), Cefoperazone + Sulbactam (77.22\%), Netilmicin (75.47\%) and Amikacin $(75.00 \%)$. All these observation was in agreement with the study by G. Suguneswari et al.[9]

In our study, the prevalence of ESBLs is $67.45 \%$. A study which was done by Harakuni et al reported a similar high prevalence of the ESBLs (74\%).[10] Laghawe et al reported $19.67 \%$ ESBL producers.[11] It has been proved that the prevalence of the ESBLs varies from country to country and even from institution to institution within the same country. In our study, the AmpC production was seen in 16.98\% isolates in concordance with the other studies. It was $17.3 \%$ in Kolkata,[12] 22.9\% in a study which was done by Bandekar et al[13] and a study which was done by Bhattacharjee et al showed 22\% AmpC production.[14] In the present study, the MBL producers were $3.30 \%$. The study which was done by Bandekar et al reported 15.7\% MBL producers. [13] The low prevalence of the MBL producers in our study could be due to the differences in the geographical distribution, which may have produced variations in the prevalence of the $\beta$ lactamases which may have been present in the different organisms, which may have given rise to the varied resistance patterns.

The increase in the prevalence of the AmpC, MBL and the ESBL producing isolates may be indicative of the increasing trend of more and more isolates acquiring the resistance, thus rendering the antimicrobial treatment ineffectively.

\section{CONCLUSION}

Pyogenic infection has been the major cause of morbidity since long. Emerging multidrug resistant strains is of major concern to treat these conditions. Appropriate and judicious selection of antibiotics by using antibiotic sensitivity data would limit the emerging drug resistant strains in the future to treat these clinical conditions successfully.

\section{REFERENCES}

[1] Koneman WK, Allen SD, Janda WM, et al. Color Atlas and Textbook of diagnostic microbiology. $6^{\text {th }}$ edn. Philadelphia: Lippincott-Raven Publisher 2005: p. 624-62.

[2] Collee JG, Marmion BP, Fraser AG, et al. Mackie and McCartney Practical medical microbiology. 14th edn. Edinburgh: Churchill Livingstone 2007.
[3] Clinical and Laboratory Standards Institute. Performance Standards for Antimicrobial Susceptibility Testing, Approved Standard. TwentySixth Informational Supplement. CLSI Document M100-S26. Wayne, PA: Clinical and Laboratory Standards Institute, 2016.

[4] Forbes BA, Sahm DF, Weissfeld AS, et al. Bailey \& Scott's Diagnostic Microbiology. $12^{\text {th }}$ edn. St. Louis, Mo: Elsevier Mosby 2007: p. 210.

[5] Zubair M, Malik A, Ahmad J. Clinico-microbiological study and antimicrobial drug resistance profile of diabetic foot infections in North India. Foot (Edinb) 2011;21(1):6-14.

[6] Agnihotri N, Gupta V, Joshi RM. Aerobic bacterial isolates from burn wound infections and their antibiograms--a five-year study. Burns 2004;30(3):241-3.

[7] Ghosh A, Karmakar PS, Pal J, et al. Bacterial incidence and antibiotic sensitivity pattern in moderate and severe infections in hospitalized patients. J Indian Med Assoc 2009;107(1):21-2, 24-5.

[8] Basu S, Panray RT, Singh BT, et al. A prospective, descriptive study to identify the microbiological profile of chronic wounds in outpatients. Ostomy Wound Manage 2009;55(1):14-20.

[9] Suguneswari G, Singh HA, Basu R. Bacteriological profile of osteomyelitis in a tertiary care hospital at Visakhapatnam, Andhra Pradesh. Int J Cur Res Rev 2013;05(20):52-8.

[10] Harakuni S, Karadesai SG, Mutnal MB, et al. The prevalence of the extended spectrum $\beta$-lactamaseproducing clinical isolates of Klebsiella pneumoniae in the intensive care unit patients of a tertiary care hospital. Annals of Tropical Medicine and Health 2011;4(2):96-8.

[11] Laghawe AE, Jaitly N, Thombare V. The simultaneous detection of the ESBL and the AmpC b-Lactamases in Gram-Negative bacilli. JCDR 2012;6(4):660-3.

[12] Arora S, Bal M. The AmpC $\beta$-lactamase producing bacterial isolates at a Kolkata hospital. Ind J Med Res 2005;122(3):224-33.

[13] Bandekar N, Vinodkumar CS, Basavarajappa KG, et al. The beta lactamases mediated resistance amongst the gram negative bacilli in burn infections. Int J Biol Med Res 2011;2(3):766-70.

[14] Bhattacharjee A, Anupurba S, Guar A, et al. The prevalence of inducible AmpC $\beta$-lactamase producing Pseudomonas aeruginosa in a tertiary care hospital in northern India. Ind J Med Microbiol 2008;26(1):89-90. 